\title{
Corrigendum
}

\section{Corrigendum to "Schisandra Fruit Vinegar Lowers Lipid Profile in High-Fat Diet Rats"}

\author{
Rui Yuan, ${ }^{1}$ Guangren Sun, ${ }^{2}$ Jiaqi Gao, ${ }^{1}$ Zepeng Yu, ${ }^{1}$ Chunyan Yu, ${ }^{3}$ Chunmei Wang $\mathbb{D}^{1}$, \\ Jinghui Sun, ${ }^{1} \mathrm{He} \mathrm{Li} \mathbb{D}^{1},{ }^{1}$ and Jianguang Chen $\mathbb{D}^{1}$ \\ ${ }^{1}$ Department of Pharmacology, College of Pharmacy, Beihua University, Jilin 132013, China \\ ${ }^{2}$ Department of Food Science, College of Forestry, Beihua University, Jilin 132013, China \\ ${ }^{3}$ Department of Pathology, College of Medicine, Beihua University, Jilin 132013, China
}

Correspondence should be addressed to He Li; yitonglh@126.com and Jianguang Chen; Chenjg@beihua.edu.cn

Received 3 February 2021; Accepted 3 February 2021; Published 25 February 2021

Copyright (c) 2021 Rui Yuan et al. This is an open access article distributed under the Creative Commons Attribution License, which permits unrestricted use, distribution, and reproduction in any medium, provided the original work is properly cited.

In the article titled "Schisandra Fruit Vinegar Lowers Lipid Profile in High-Fat Diet Rats" [1], Figure 6 and Figure 1 were identical. This was a mistake on the authors' behalf, and the correct Figure 1 is shown below.

\section{References}

[1] R. Yuan, G. Sun, J. Gao et al., "Schisandra fruit vinegar lowers lipid profile in high-fat diet rats," Evidence-Based Complementary and Alternative Medicine, vol. 2020, Article ID 7083415, 10 pages, 2020. 

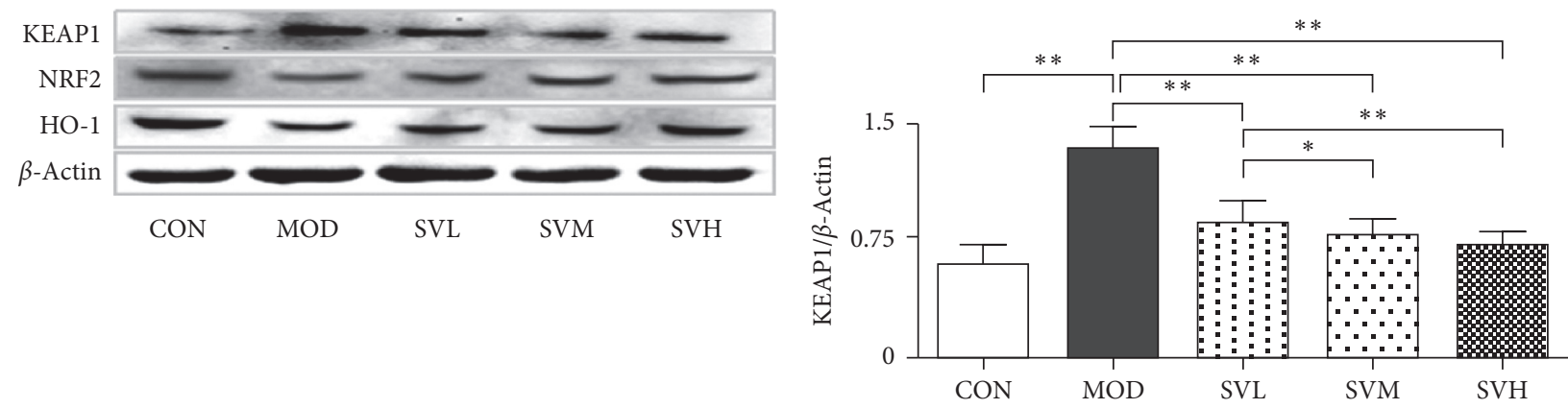

(a)

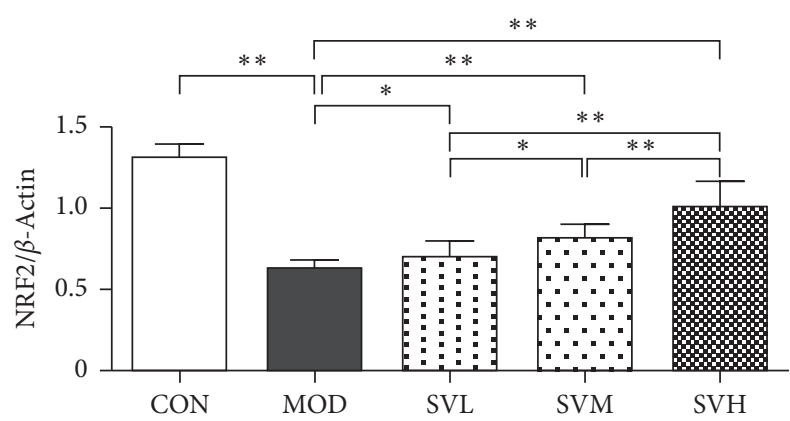

(c)

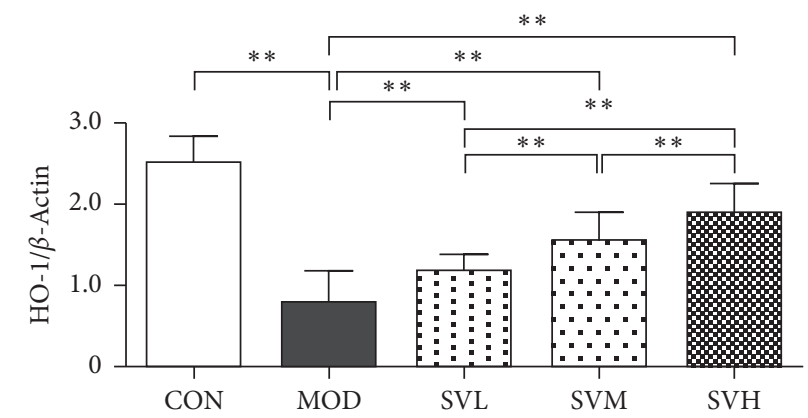

(d)

FIGURE 1: Effects of SV on the expressions of KEAP1, NRF2, and HO-1 proteins of the livers in HFD rats. After the gavage of SV to HFD rats for 6 weeks, the expressions of KEAP1, NRF2, and HO-1 proteins were measured. (a) Electrophoretogram, (b) KEAP1, (c) NRF2, and (d) HO-1. The data are shown as the mean $\pm \mathrm{SD}, n=8$. Compared between different groups, ${ }^{*} p<0.05$ and ${ }^{* *} p<0.01$. 